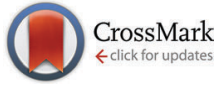

Cite this: Chem. Commun., 2015, 51, 5367

Received 11th August 2014, Accepted 5th September 2014

DOI: $10.1039 / \mathrm{c} 4 \mathrm{cc} 06307 d$

www.rsc.org/chemcomm

\section{Fine tuning the ionic liquid-vacuum outer atomic surface using ion mixtures $\dagger$}

\author{
Ignacio J. Villar-Garcia, ${ }^{a}$ Sarah Fearn, ${ }^{a}$ Nur L. Ismail, ${ }^{\mathrm{b}}$ Alastair J. S. McIntosh ${ }^{\mathrm{b}}$ and \\ Kevin R. J. Lovelock*b
}

Ionic liquid-vacuum outer atomic surfaces can be created that are remarkably different from the bulk composition. In this communication we demonstrate, using low-energy ion scattering (LEIS), that for ionic liquid mixtures the outer atomic surface shows significantly more atoms from anions with weaker cation-anion interactions (and vice versa).

The ionic liquid-gas surface is crucial for a wide range of applications: gas capture/storage/separation, nanoparticle and thin film preparation, supported ionic liquid phase (SILP) catalysis, stationary phases for gas chromatography, and ionic liquid purity. ${ }^{1}$ For absorption to occur, which is required for all of the above applications, adsorption must first occur. Adsorption is primarily controlled by the composition of the ionic liquid-gas outer atomic surface (the atomic layer of an ionic liquid which is in contact with the gas), i.e. the adsorption sites. Mixtures of ionic liquids ${ }^{2}$ give the enticing possibility of fine-tuning the ionic liquid-gas surface to give the desired adsorption sites.

The compositions of ionic liquid-gas surfaces have been probed using both spectroscopy and scattering. ${ }^{1,3}$ For simple ionic liquids (i.e. composed of one cation and one anion) it has been demonstrated that there are more alkyl chain atoms at the ionic liquidvacuum outer atomic surface than expected based upon the bulk composition. ${ }^{1,3}$ Recently, we used low-energy ion scattering (LEIS) of $\mathrm{He}^{+}$to study 23 simple ionic liquids. The appearance of characteristic Gaussian-shaped surface peaks in LEIS spectra provides unambiguous proof of the presence of any element in the outer atomic surface, and peak areas are an indication of the amount each element. ${ }^{4}$ Our results showed that the anion, and therefore hydrogen bond acceptor adsorption sites, were at the ionic liquid-vacuum outer atomic surface, establishing that

\footnotetext{
${ }^{a}$ Department of Materials, Imperial College, London, UK

${ }^{b}$ Department of Chemistry, Imperial College, London, UK.

E-mail: kevin.lovelock@imperial.ac.uk

$\dagger$ Electronic supplementary information (ESI) available: Ionic liquid synthesis, LEIS apparatus and spectra quantification, demonstration of the equilibrium nature of our LEIS experiments, calculations to determine ideal ionic liquidvacuum surface compositions. See DOI: 10.1039/c4cc06307d
}

the outer atomic surface of ionic liquids was not composed solely of alkyl chains. ${ }^{5}$ Research on fine-tuning the ionic liquid-vacuum surface using ion mixtures to give the desired adsorption sites is in its infancy. Using Rutherford backscattering (RBS) the surface layer composition of a set of mixtures was found to be approximately the same as in the bulk liquid, i.e. near-ideal. ${ }^{6}$ However, it must be noted that RBS does not exclusively probe the ionic liquid-vacuum outer atomic surface, as LEIS does.

Here we have used LEIS to investigate three ionic liquid binary mixture systems, all containing the $\left[\mathrm{C}_{4} \mathrm{C}_{1} \mathrm{Im}\right]^{+}$cation and two anions, as shown in Scheme 1: $\left[\mathrm{C}_{4} \mathrm{C}_{1} \operatorname{Im}\right] \mathrm{I}_{1-x}\left[\mathrm{Tf}_{2} \mathrm{~N}\right]_{x},\left[\mathrm{C}_{4} \mathrm{C}_{1} \operatorname{Im}\right] \mathrm{Cl}_{1-x}\left[\mathrm{Tf}_{2} \mathrm{~N}\right]_{x}$, and $\left[\mathrm{C}_{4} \mathrm{C}_{1} \mathrm{Im}\right]\left[\mathrm{HOSO}_{3}\right]_{1-x}\left[\mathrm{BF}_{4}\right]_{x}$. $\left[\mathrm{C}_{4} \mathrm{C}_{1} \mathrm{Im}\right] \mathrm{Cl}$ (i.e. $x=0$ for $\left[\mathrm{C}_{4} \mathrm{C}_{1} \mathrm{Im}\right]-$ $\mathrm{Cl}_{1-x}\left[\mathrm{Tf}_{2} \mathrm{~N}\right]_{x}$ ) was not studied as it is a solid at room temperature. These mixtures were chosen because: (i) of their miscibility at room temperature, (ii) the anions in the mixtures have significantly different cation-anion intermolecular interactions, and (iii) $\left[\mathrm{Tf}_{2} \mathrm{~N}\right]^{-}$and the halide ions are very different in size whilst $\left[\mathrm{HOSO}_{3}\right]^{-}$and $\left[\mathrm{BF}_{4}\right]^{-}$are very similar in size (see ESI $\dagger$ for details on the molecular volume, $V_{\text {mol }}$, of each simple ionic liquid). Understanding the impact of cation-anion intermolecular interactions and ion size on ionic liquid-vacuum surface composition will provide a guide as to whether enthalpy or entropy dominates surface formation.

Absolute determination of the outer atomic surface concentration of each element using LEIS for the ionic liquids studied

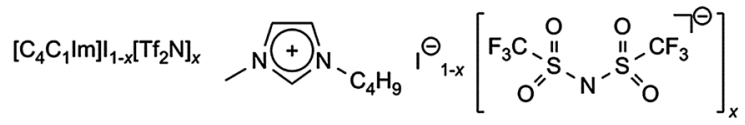

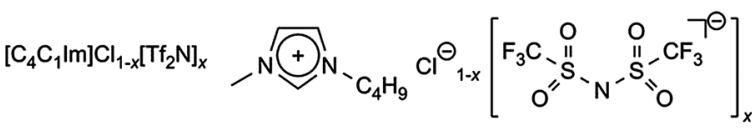

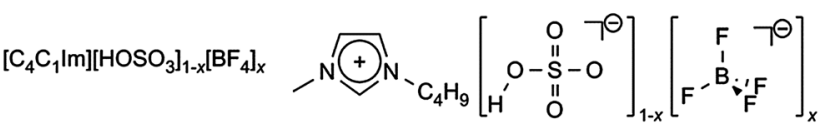

Scheme 1 Three ionic liquid mixture systems investigated in this communication. 
is not possible at present. However, the scattered ion yield for each element in each LEIS spectrum, $Y_{\mathrm{i}}$ (the area under the Gaussian peak), is proportional to the outer atomic surface concentration of each element (see ESI $\dagger$ for more details). Therefore, the percentage of outer atomic surface atoms for an element in the mixtures relative to the simple ionic liquid can be determined. This percentage can be compared to the percentage of atoms in an ideal case (i.e. when the bulk and surface of the mixture have the same composition) in order to get an estimation of the deviation from ideality. The amount of each element in the bulk liquid is calculated based upon the stoichiometry of the mixture, excluding the very small hydrogen atoms (see $\mathrm{ESI} \dagger$ for more details). The ideal surface composition trends over the whole range of $x$ are plotted as solid lines in Fig. 1b and $\mathrm{c}$ for $\left[\mathrm{C}_{4} \mathrm{C}_{1} \mathrm{Im}\right] \mathrm{I}_{1-x}\left[\mathrm{Tf}_{2} \mathrm{~N}\right]_{x}$ and $\left[\mathrm{C}_{4} \mathrm{C}_{1} \operatorname{Im}\right] \mathrm{Cl}_{1-x}\left[\mathrm{Tf}_{2} \mathrm{~N}\right]_{x}$ (curved) and in Fig. $2 \mathrm{~b}$ and $\mathrm{c}$ for $\left[\mathrm{C}_{4} \mathrm{C}_{1} \mathrm{Im}\right]\left[\mathrm{HOSO}_{3}\right]_{1-x}\left[\mathrm{BF}_{4}\right]_{x}$ (linear). Plots of $Y_{\mathrm{i}}$ against the energy of scattered $\mathrm{He}^{+}$are given in Fig. S5 and $\mathrm{S} 6$ (ESI $\dagger$ ).

For $\left[\mathrm{C}_{4} \mathrm{C}_{1} \mathrm{Im}\right] \mathrm{I}_{1-x}\left[\mathrm{Tf}_{2} \mathrm{~N}\right]_{x}$ Gaussian-shaped surface peaks were observed in the LEIS spectra for all mixtures due to scattering of $\mathrm{He}^{+}$ from surface fluorine and oxygen atoms (Fig. 1a). In addition, a peak due to scattering of $\mathrm{He}^{+}$from surface and sub-surface sulfur atoms was observed for all mixtures (Fig. 1a); the process for producing peaks due to sub-surface atoms is explained in the ESI. $\dagger$ A peak due to nitrogen was not observed for any mixtures, as expected based upon LEIS of simple ionic liquids. ${ }^{5}$ Excitingly, surface peaks due to scattering of $\mathrm{He}^{+}$from $\mathrm{I}^{-}$were observed only for $x\left(\left[\mathrm{Tf}_{2} \mathrm{~N}\right]^{-}\right)=0,0.02$ and 0.1 ; no $\mathrm{I}^{-}$was observed at the outer atomic surface when $x\left(\left[\mathrm{Tf}_{2} \mathrm{~N}\right]^{-}\right) \geq 0.2$ (Fig. 1a, and the ESI $\dagger$ for details on fitting the LEIS spectra). This staggering observation means that the addition of a very small amount of $\left[\mathrm{C}_{4} \mathrm{C}_{1} \mathrm{Im}\right]\left[\mathrm{Tf}_{2} \mathrm{~N}\right]$ to $\left[\mathrm{C}_{4} \mathrm{C}_{1} \mathrm{Im}\right] \mathrm{I}$ changed the ionic liquid-vacuum outer atomic surface dramatically (Fig. 1). For $\left[\mathrm{C}_{4} \mathrm{C}_{1} \mathrm{Im}\right] \mathrm{I}_{1-x}\left[\mathrm{Tf}_{2} \mathrm{~N}\right]_{x}$ the amount of fluorine and oxygen increased dramatically and the amount of $\mathrm{I}^{-}$decreased dramatically from $x\left(\left[\mathrm{Tf}_{2} \mathrm{~N}\right]^{-}\right)=0$ to $x\left(\left[\mathrm{Tf}_{2} \mathrm{~N}\right]^{-}\right)=0.1$ (Fig. $1 \mathrm{~b}$ and $\mathrm{c}$ and Fig. S5d, ESI $\dagger$ ). The differences between the measured surface amounts and the ideal surface amounts are huge at $x\left(\left[\mathrm{Tf}_{2} \mathrm{~N}\right]^{-}\right) \leq 0.3$ (Fig. 1b and c). Overall, for $\left[\mathrm{C}_{4} \mathrm{C}_{1} \mathrm{Im}\right] \mathrm{I}_{1-x}\left[\mathrm{Tf}_{2} \mathrm{~N}\right]_{x}$ there were significantly more $\left[\mathrm{Tf}_{2} \mathrm{~N}\right]^{-}$ atoms (i.e. fluorine, oxygen) and fewer $\mathrm{I}^{-}$at the ionic liquid-vacuum outer atomic surface than expected for ideal surface compositions.

Similar results were observed for $\left[\mathrm{C}_{4} \mathrm{C}_{1} \mathrm{Im}\right] \mathrm{Cl}_{1-x}\left[\mathrm{Tf}_{2} \mathrm{~N}\right]_{x}$ (Fig. S4, $\mathrm{ESI} \dagger$ ) as for $\left[\mathrm{C}_{4} \mathrm{C}_{1} \mathrm{Im}\right] \mathrm{I}_{1-x}\left[\mathrm{Tf}_{2} \mathrm{~N}\right]_{x}$; there were more $\left[\mathrm{Tf}_{2} \mathrm{~N}\right]^{-}$atoms (i.e. fluorine, oxygen) at the ionic liquid-vacuum outer atomic surface than expected for ideal surface compositions. In addition, for both $\left[\mathrm{C}_{4} \mathrm{C}_{1} \mathrm{Im}\right] \mathrm{I}_{1-x}\left[\mathrm{Tf}_{2} \mathrm{~N}\right]_{x}$ and $\left[\mathrm{C}_{4} \mathrm{C}_{1} \operatorname{Im}\right] \mathrm{Cl}_{1-x}\left[\mathrm{Tf}_{2} \mathrm{~N}\right]_{x}$ the amount of outer atomic surface fluorine matched for all $x\left(\left[\mathrm{Tf}_{2} \mathrm{~N}\right]^{-}\right)$, within the error of the experiment (Fig. 1b), further confirming the similarity of results for the mixtures of $\left[\mathrm{C}_{4} \mathrm{C}_{1} \operatorname{Im}\right] \mathrm{I}_{1-x}\left[\mathrm{Tf}_{2} \mathrm{~N}\right]_{x}$ and $\left[\mathrm{C}_{4} \mathrm{C}_{1} \operatorname{Im}_{3}\right] \mathrm{Cl}_{1-x}\left[\mathrm{Tf}_{2} \mathrm{~N}\right]_{x}$. For $\left[\mathrm{C}_{4} \mathrm{C}_{1} \mathrm{Im}\right] \mathrm{Cl}_{1-x}\left[\mathrm{Tf}_{2} \mathrm{~N}\right]_{x}$ a peak due to $\mathrm{He}^{+}$scattering from chlorine atoms occurred at $\sim 1910 \mathrm{eV}$ for all $x\left(\left[\mathrm{Tf}_{2} \mathrm{~N}\right]^{-}\right.$) studied (Fig. S4, ESI $\dagger$ ). Due to the very small chlorine peak area and the sulfur region at $1790 \mathrm{eV}$ to $1835 \mathrm{eV}$, we cannot determine whether this chlorine peak was Gaussian-shaped; therefore, at present for the mixtures we cannot determine if chlorine anions were at the ionic liquidvacuum outer atomic surface.

For $\left[\mathrm{C}_{4} \mathrm{C}_{1} \mathrm{Im}\right]\left[\mathrm{HOSO}_{3}\right]_{1-x}\left[\mathrm{BF}_{4}\right]_{x}$ Gaussian-shaped surface fluorine peaks were observed in the LEIS spectra for all mixtures studied due to scattering of $\mathrm{He}^{+}$from surface fluorine atoms (Fig. 2a);
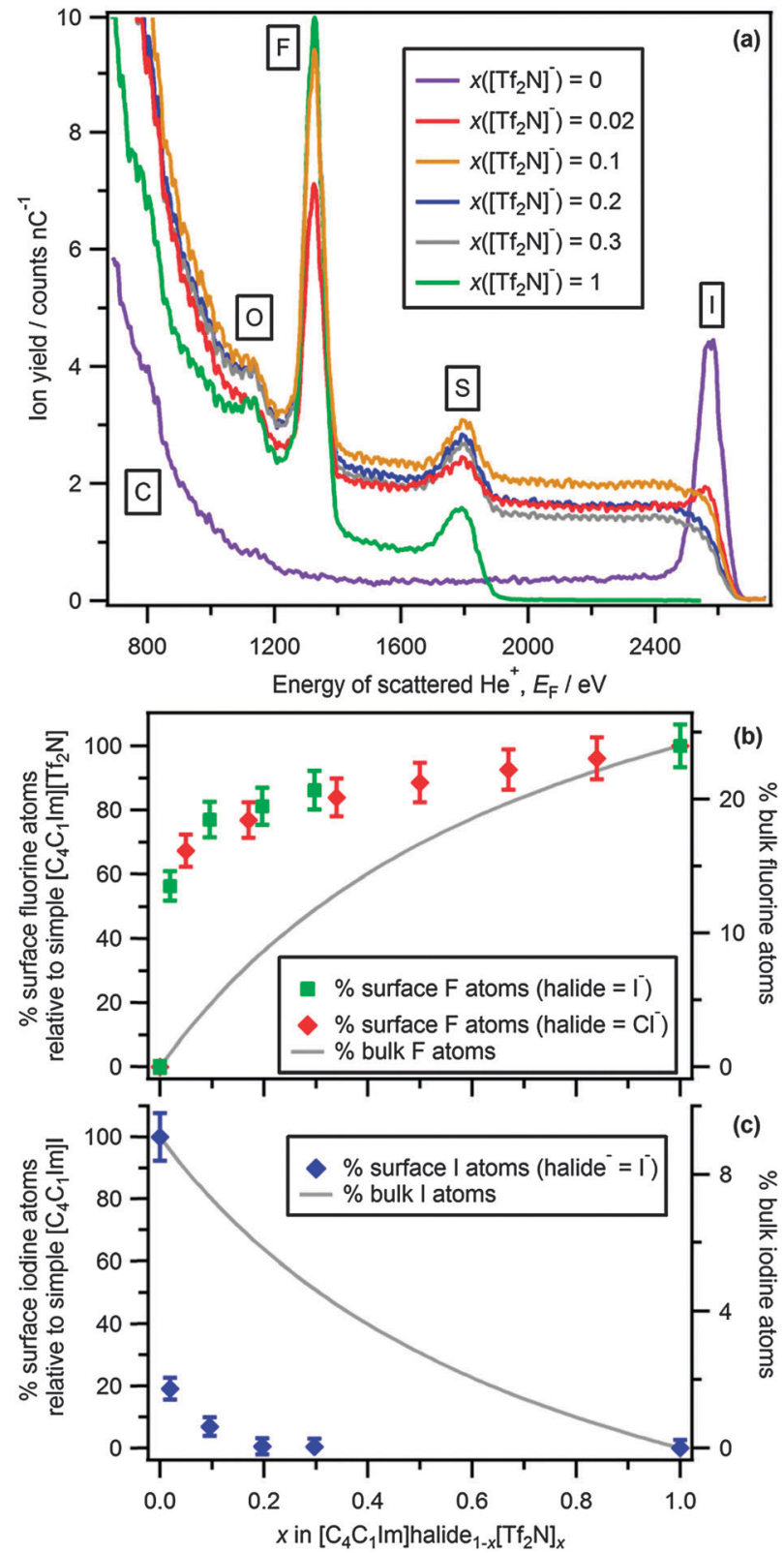

Fig. 1 (a) LEIS spectra $\left({ }^{4} \mathrm{He}^{+}, E_{0}=3 \mathrm{keV}\right)$ for $\left.\left[\mathrm{C}_{4} \mathrm{C}_{1} \mid \mathrm{m}\right]\right]_{1-x}\left[\mathrm{Tf}_{2} \mathrm{~N}\right]_{x}$ where $x\left(\left[\mathrm{Tf}_{2} \mathrm{~N}\right]^{-}\right)=0,0.02,0.1,0.2,0.3$ and 1. (b) \% surface fluorine atoms relative to simple $\left[\mathrm{C}_{4} \mathrm{C}_{1} \mathrm{Im}\right]\left[\mathrm{Tf}_{2} \mathrm{~N}\right]$ from LEIS data (left axis) and \% bulk fluorine atoms (which represents an ideal outer atomic surface composition, right axis) vs. mole fraction $x\left(\left[T f_{2} N\right]^{-}\right)$for $\left.\left[\mathrm{C}_{4} \mathrm{C}_{1} \mid \mathrm{m}\right]\right]_{1-x}\left[\mathrm{Tf}_{2} \mathrm{~N}\right]_{x}$ and $\left[\mathrm{C}_{4} \mathrm{C}_{1} \mid \mathrm{m}\right] \mathrm{Cl}_{1-x}\left[\mathrm{Tf}_{2} \mathrm{~N}\right]_{x}$. (c) \% surface iodine atoms relative to simple $\left[\mathrm{C}_{4} \mathrm{C}_{1} \mathrm{Im}\right] \mathrm{I}$ (left axis) and \% bulk iodine atoms (which represents an ideal outer atomic surface composition, right axis) vs. mole fraction $x\left(\left[T f_{2} N\right]^{-}\right)$for $\left.\left[\mathrm{C}_{4} \mathrm{C}_{1} \mid m\right]\right]_{1-x}\left[T f_{2} N\right]_{x}$.

therefore, for $\left[\mathrm{C}_{4} \mathrm{C}_{1} \mathrm{Im}\right]\left[\mathrm{HOSO}_{3}\right]_{1-x}\left[\mathrm{BF}_{4}\right]_{x}$ for all mixtures studied there was a significant concentration of fluorine atoms at the ionic liquid-vacuum outer atomic surface. For $\left[\mathrm{C}_{4} \mathrm{C}_{1} \mathrm{Im}\right]\left[\mathrm{HOSO}_{3}\right]_{1-x}\left[\mathrm{BF}_{4}\right]_{x}$ peaks due to boron or nitrogen were not observed, as expected based upon LEIS of simple ionic liquids. ${ }^{5}$ Strikingly, for $\left[\mathrm{C}_{4} \mathrm{C}_{1} \mathrm{Im}\right]\left[\mathrm{HOSO}_{3}\right]_{1-x}\left[\mathrm{BF}_{4}\right]_{x}$ peaks were observed due to scattering of $\mathrm{He}^{+}$from surface oxygen atoms, and both surface and subsurface sulfur atoms (Fig. 2a and c) only where $x\left(\left[\mathrm{BF}_{4}\right]^{-}\right) \leq 0.25$. 

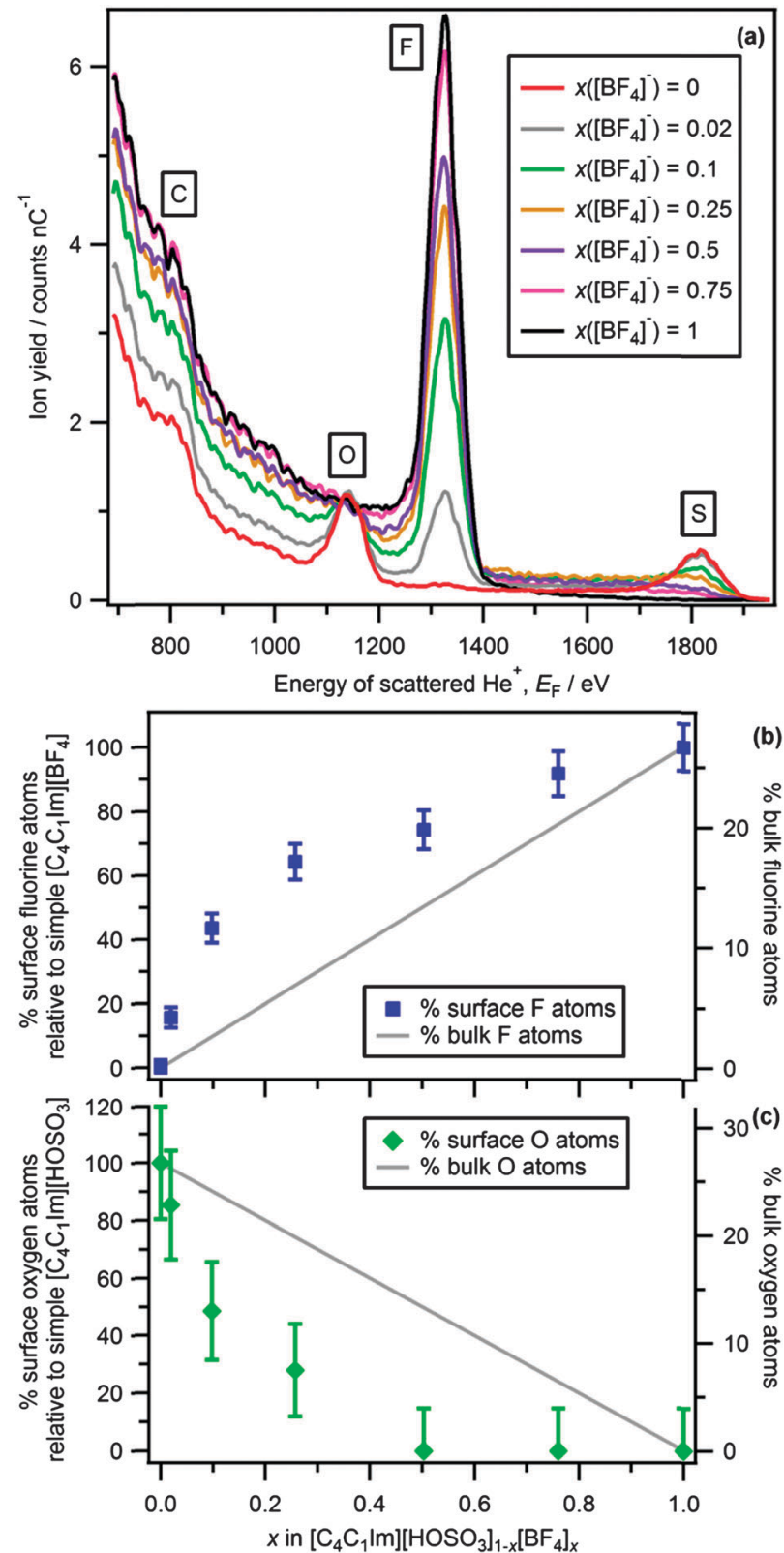

Fig. 2 (a) LEIS spectra $\left({ }^{4} \mathrm{He}^{+}, E_{0}=3 \mathrm{keV}\right)$ for $\left[\mathrm{C}_{4} \mathrm{C}_{1} \mathrm{Im}\right]\left[\mathrm{HOSO}_{3}\right]_{1-x}\left[\mathrm{BF}_{4}\right]_{x}$ where $x\left(\left[\mathrm{BF}_{4}\right]^{-}\right)=0,0.02,0.1,0.25,0.5,0.75$ and 1 . (b) \% surface fluorine atoms relative to simple $\left[\mathrm{C}_{4} \mathrm{C}_{1} \mathrm{Im}\right]\left[\mathrm{BF}_{4}\right]$ from LEIS data (left axis) and \% bulk fluorine atoms (which represents an ideal outer atomic surface composition, right axis) vs. mole fraction $x\left(\left[\mathrm{BF}_{4}\right]^{-}\right)$for $\left[\mathrm{C}_{4} \mathrm{C}_{1} \mathrm{Im}\right]\left[\mathrm{HOSO}_{3}\right]_{1-x}\left[\mathrm{BF}_{4}\right]_{x}$. (c) \% surface oxygen atoms relative to simple $\left[\mathrm{C}_{4} \mathrm{C}_{1} \mathrm{Im}\right]\left[\mathrm{HOSO}_{3}\right]$ from LEIS data (left axis) and \% bulk oxygen atoms (which represents an ideal outer atomic surface composition, right axis) vs. mole fraction $x\left(\left[\mathrm{BF}_{4}\right]^{-}\right)$for $\left[\mathrm{C}_{4} \mathrm{C}_{1} \mathrm{Im}\right]\left[\mathrm{HOSO}_{3}\right]_{1-x}\left[\mathrm{BF}_{4}\right]_{x}$.

Above this concentration, i.e. $x\left(\left[\mathrm{BF}_{4}\right]^{-}\right) \geq 0.5$, there was not a significant concentration of oxygen or sulfur atoms at the ionic liquid-vacuum outer atomic surface. The differences between the measured surface amounts and the ideal surface amounts are far greater than the error at $x\left(\left[\mathrm{BF}_{4}\right]^{-}\right) \leq 0.5$ (Fig. 2b and c). Overall, for $\left[\mathrm{C}_{4} \mathrm{C}_{1} \mathrm{Im}\right]\left[\mathrm{HOSO}_{3}\right]_{1-x}\left[\mathrm{BF}_{4}\right]_{x}$ there were more atoms from $\left[\mathrm{BF}_{4}\right]^{-}$ and fewer atoms from $\left[\mathrm{HOSO}_{3}\right]^{-}$at the outer atomic surface than expected for ideal surface compositions.
For $\left[\mathrm{C}_{4} \mathrm{C}_{1} \mathrm{Im}\right] \mathrm{I}_{0.8}\left[\mathrm{Tf}_{2} \mathrm{~N}\right]_{0.2}$ no iodine peak was observed, but the amount of fluorine atoms at the outer atomic surface was smaller than the amount of fluorine atoms for simple $\left[\mathrm{C}_{4} \mathrm{C}_{1} \mathrm{Im}\right]\left[\mathrm{Tf}_{2} \mathrm{~N}\right]$ (Fig. 1). For $\left[\mathrm{C}_{4} \mathrm{C}_{1} \mathrm{Im}\right]\left[\mathrm{HOSO}_{3}\right]_{0.5}\left[\mathrm{BF}_{4}\right]_{0.5}$ no oxygen or sulfur peaks were observed, but the amount of fluorine atoms at the outer atomic surface was smaller than the amount of fluorine atoms for simple $\left[\mathrm{C}_{4} \mathrm{C}_{1} \mathrm{Im}\right]\left[\mathrm{BF}_{4}\right]$ (Fig. 2). Therefore, for both of the mixtures discussed in this paragraph there were in total fewer anionic atoms at the outer atomic surface than expected for an ideal surface composition of the mixture. These results point towards the presence of more cationic atoms, i.e. carbon and hydrogen, at the outer atomic surface than expected for an ideal surface composition. However, this tentative conclusion needs to be checked using techniques such as oxygen scattering (which can be used to investigate the amount of hydrogen atoms at the outer atomic surface). ${ }^{3 b}$

Most ionic liquid mixtures exhibit near-ideal bulk behaviour, and most ionic liquids are miscible at room temperature. ${ }^{2}$ However, for ionic liquids composed of ions with very different sizes, the entropy of mixing can be sufficiently negative for immiscibility to occur. ${ }^{7}$ The outer atomic surfaces of the mixture systems we have investigated here show strong deviations from ideality. Our observed trends in outer atomic surface composition can be explained by the strength of the intermolecular cation-anion interactions, i.e. enthalpic driving forces. The strength of the intermolecular cation-anion interactions can be judged by the cohesive energy densities or the Kamlet-Taft hydrogen bond acceptor number, $\beta$ (see ESI, $\dagger$ Table S5, for more details on these values). Cation-anion interactions are significantly weaker for $\left[\mathrm{C}_{4} \mathrm{C}_{1} \mathrm{Im}\right]\left[\mathrm{Tf}_{2} \mathrm{~N}\right]$ than for $\left[\mathrm{C}_{4} \mathrm{C}_{1} \mathrm{Im}\right] \mathrm{Cl}$ and $\left[\mathrm{C}_{4} \mathrm{C}_{1} \mathrm{Im}\right] \mathrm{I} ; \beta$ for $\left[\mathrm{C}_{4} \mathrm{C}_{1} \mathrm{Im}\right] \mathrm{Cl}$ and $\left[\mathrm{C}_{4} \mathrm{C}_{1} \mathrm{Im}\right] \mathrm{I}$ are significantly larger than for $\left[\mathrm{C}_{4} \mathrm{C}_{1} \mathrm{Im}\right]\left[\mathrm{Tf}_{2} \mathrm{~N}\right],{ }^{8}$ and the cohesive energy densities for $\left[\mathrm{C}_{8} \mathrm{C}_{1} \mathrm{Im}\right] \mathrm{Cl}$ and $\left[\mathrm{C}_{8} \mathrm{C}_{1} \mathrm{Im}\right] \mathrm{I}$ are significantly larger than for $\left[\mathrm{C}_{8} \mathrm{C}_{1} \operatorname{Im}\right]\left[\mathrm{Tf}_{2} \mathrm{~N}\right]{ }^{9}$ Cation-anion interactions are significantly weaker for $\left[\mathrm{C}_{4} \mathrm{C}_{1} \mathrm{Im}\right]\left[\mathrm{BF}_{4}\right]$ than for $\left[\mathrm{C}_{4} \mathrm{C}_{1} \mathrm{Im}\right]\left[\mathrm{HOSO}_{3}\right] ; \beta$ for $\left[\mathrm{C}_{4} \mathrm{C}_{1} \mathrm{Im}\right]\left[\mathrm{HOSO}_{3}\right]$ is significantly larger than for $\left[\mathrm{C}_{4} \mathrm{C}_{1} \mathrm{Im}\right]\left[\mathrm{BF}_{4}\right]^{10}{ }^{10}$ Therefore, for all mixtures studied here the anion with weaker cation-anion intermolecular interactions had significantly more outer atomic surface atoms than expected for an ideal outer atomic surface. This observation can be explained by the following: cation-anion interactions must be broken to form the ionic liquid-vacuum surface, i.e. they are missing the interactions from the vacuum side that would occur when in the bulk liquid. Therefore, the weakest cation-anion interactions are most readily broken, leading to an outer atomic surface with more of such ions than expected for an ideal surface. For the mixtures containing very similarly sized anions $\left(\left[\mathrm{C}_{4} \mathrm{C}_{1} \mathrm{Im}\right]\left[\mathrm{HOSO}_{3}\right]_{1-x}\left[\mathrm{BF}_{4}\right]_{x}\right)$ we found significantly more outer atomic surface atoms of one anion over the other. We can conclude that the anion size appears to have little impact upon the ionic liquid-vacuum outer atomic surface composition, and cation-anion intermolecular interactions dominate surface formation.

In this work, we have studied a very similar mixture to that studied using RBS; the only difference is the cation alkyl chain length, $\left[\mathrm{C}_{4} \mathrm{C}_{1} \mathrm{Im}\right] \mathrm{Cl}_{0.5}\left[\mathrm{Tf}_{2} \mathrm{~N}\right]_{0.5}$ vs. $\left[\mathrm{C}_{6} \mathrm{C}_{1} \mathrm{Im}\right] \mathrm{Cl}_{0.5}\left[\mathrm{Tf}_{2} \mathrm{~N}\right]_{0.5}{ }^{6}$ We have found significantly more outer atomic surface atoms from $\left[\mathrm{Tf}_{2} \mathrm{~N}\right]^{-}$, whereas using RBS for $\left[\mathrm{C}_{6} \mathrm{C}_{1} \mathrm{Im}\right] \mathrm{Cl}_{0.5}\left[\mathrm{Tf}_{2} \mathrm{~N}\right]_{0.5}$ the ratio of $\left[\mathrm{Tf}_{2} \mathrm{~N}\right]^{-}$ to $\mathrm{Cl}^{-}$was approximately $1: 1$ in the surface layer. ${ }^{6}$ We believe 
this difference is due mainly to the greater surface sensitivity of LEIS compared to RBS; the different alkyl chain lengths may play a part, although we expect this effect to be relatively unimportant. In addition, our results shed significant light upon a study of a SILP model system, $\left[\mathrm{Pt}\left(\mathrm{NH}_{3}\right)_{4}\right] \mathrm{Cl}_{2}$ dissolved in $\left[\mathrm{C}_{2} \mathrm{C}_{1} \mathrm{Im}\right]\left[\mathrm{C}_{2} \mathrm{OSO}_{3}\right]$ $\left(\left[\mathrm{C}_{2} \mathrm{OSO}_{3}\right]^{-}=\right.$ethylsulfate $) .{ }^{11}$ For SILP catalysis, the reaction is likely to occur near to the ionic liquid-gas outer atomic surface (which minimises mass transfer limitations). Therefore, a surface-active catalyst will minimise the amount of catalyst needed in the system. It was found that the soft Pt complex ions were enriched in the surface layer, and $\mathrm{Cl}^{-}$were depleted. ${ }^{11}$ The depletion of $\mathrm{Cl}^{-}$ agrees with our results here; cation-Cl intermolecular interactions are expected to be the strongest in this ion mixture. The intermolecular interactions between $\left[\mathrm{Pt}\left(\mathrm{NH}_{3}\right)_{4}\right]^{2+}$ and $\left[\mathrm{C}_{2} \mathrm{OSO}_{3}\right]^{-}$ are likely to be weaker than the intermolecular interactions between $\left[\mathrm{C}_{2} \mathrm{C}_{1} \mathrm{Im}\right]^{+}$and $\left[\mathrm{C}_{2} \mathrm{OSO}_{3}\right]^{-}$, leading to more $\left[\mathrm{Pt}\left(\mathrm{NH}_{3}\right)_{4}\right]^{2+}$ in the surface layer than for an ideal surface.

We have demonstrated using careful choices of ion mixtures that the ionic liquid-vacuum outer atomic surface composition can be very different to the ideal surface composition, allowing one to fine-tune the ionic liquid-vacuum outer atomic surface for different applications. For example, it is possible that the kinetics of water adsorption would be slowed by adding a small amount of $\left[\mathrm{C}_{4} \mathrm{C}_{1} \mathrm{Im}\right]\left[\mathrm{Tf}_{2} \mathrm{~N}\right]$ to $\left[\mathrm{C}_{4} \mathrm{C}_{1} \mathrm{Im}\right] \mathrm{I}$, as adding a small amount of $\left[\mathrm{C}_{4} \mathrm{C}_{1} \mathrm{Im}\right]\left[\mathrm{Tf}_{2} \mathrm{~N}\right]$ to $\left[\mathrm{C}_{4} \mathrm{C}_{1} \mathrm{Im}\right] \mathrm{I}$ would greatly reduce the number of hydrogen bond acceptor adsorption sites at the ionic liquid-vacuum outer atomic surface. In addition, our findings advocate the use of catalysts with weaker cation-anion intermolecular interactions than the ionic liquid support, thus maximising the amount of catalyst at the outer atomic surface. Finally, our results show that low bulk amounts of ionic impurities may substantially affect the surface chemistry of ionic liquids for any application.
KRJL acknowledges Imperial College London for the award of a Junior Research Fellowship, and thanks Prof. Tom Welton for his help and excellent guidance. SF acknowledges support from the EPRSC, EP/H006060/1 for the purchase of the LEIS instrument. IJVG acknowledge support from the EPSRC, EP/ J021199/1. Dr Richard Matthews is thanked for his help with the graphical abstract. Richard Fogarty is thanked for his help with sample preparation.

\section{Notes and references}

1 (a) C. S. Santos and S. Baldelli, Chem. Soc. Rev., 2010, 39, 2136; (b) K. R. J. Lovelock, Phys. Chem. Chem. Phys., 2012, 14, 5071.

2 H. Niedermeyer, J. P. Hallett, I. J. Villar-Garcia, P. A. Hunt and T. Welton, Chem. Soc. Rev., 2012, 41, 7780.

3 (a) K. R. J. Lovelock, I. J. Villar-Garcia, F. Maier, H. P. Steinrück and P. Licence, Chem. Rev., 2010, 110, 5158; (b) C. Waring, P. A. J. Bagot, M. L. Costen and K. G. McKendrick, J. Phys. Chem. Lett., 2011, 2, 12; (c) G. Andersson and C. Ridings, Chem. Rev., 2014, 114, 8361.

4 H. H. Brongersma, in Characterization of materials, ed. E. N. Kaufmann, Wiley, Hoboken, 2012, pp. 1-23.

5 I. J. Villar-Garcia, S. Fearn, G. F. De Gregorio, N. L. Ismail, F. J. V. Gschwend, A. J. S. McIntosh and K. R. J. Lovelock, Chem. Sci., 2014, DOI: 10.1039/C4SC00640B.

6 K. Nakajima, S. Oshima, M. Suzuki and K. Kimura, Surf. Sci., 2012, 606, 1693.

7 A. Arce, M. J. Earle, S. P. Katdare, H. Rodriguez and K. R. Seddon, Chem. Commun., 2006, 2548.

8 R. Lungwitz, V. Strehmel and S. Spange, New J. Chem., 2010, 34, 1135.

9 K. R. J. Lovelock, J. P. Armstrong, P. Licence and R. G. Jones, Phys. Chem. Chem. Phys., 2014, 16, 1339.

10 (a) A. Brandt, M. J. Ray, T. Q. To, D. J. Leak, R. J. Murphy and T. Welton, Green Chem., 2011, 13, 2489; (b) M. A. Ab Rani, A. Brandt, L. Crowhurst, A. Dolan, N. H. Hassan, J. P. Hallett, P. A. Hunt, M. Lui, H. Niedermeyer, J. M. Perez-Arlandis, M. Schrems, T. Q. To, T. Welton and R. Wilding, Phys. Chem. Chem. Phys., 2011, 13, 16831.

11 F. Maier, J. M. Gottfried, J. Rossa, D. Gerhard, P. S. Schulz, W. Schwieger, P. Wasserscheid and H. P. Steinrück, Angew. Chem., Int. Ed., 2006, 45, 7778. 